OPEN ACCESS

Edited by:

Naser A. Anjum,

Aligarh Muslim University, India

Reviewed by:

Yong Zhang,

Fujian Normal University, China

Zengling $\mathrm{Ma}$,

Wenzhou University, China

*Correspondence:

Renjun Wang

wangrenjun2002@126.com

Qian Liu

lqian0526@126.com

${ }^{\dagger}$ These authors have contributed equally to this work

Specialty section: This article was submitted to Marine Pollution,

a section of the journa Frontiers in Marine Science

Received: 12 October 2021 Accepted: 10 December 2021

Published: 11 January 2022

Citation:

Wang R and Liu Q (2022)

Responses of Bloom-Forming

Heterosigma akashiwo

to Allelochemical Linoleic Acid: Growth Inhibition, Oxidative Stress

and Apoptosis.

Front. Mar. Sci. 8:793567. doi: 10.3389/fmars.2021.793567

\section{Responses of Bloom-Forming Heterosigma akashiwo to Allelochemical Linoleic Acid: Growth Inhibition, Oxidative Stress and Apoptosis}

\author{
Renjun Wang ${ }^{1 * \dagger}$ and Qian Liu ${ }^{2,3 * t}$ \\ ${ }^{1}$ College of Life Sciences, Qufu Normal University, Qufu, China, ${ }^{2}$ College of Marine Life Science, Ocean University of China, \\ Qingdao, China, ${ }^{3}$ Laboratory for Marine Ecology and Environmental Science, Pilot National Laboratory for Marine Science \\ and Technology, Qingdao, China
}

Algal blooms have been occurring in many regions worldwide, and allelochemicals are important algaecides used to control harmful algal blooms (HABs). The allelopathic effects of linoleic acid (LA) on the harmful raphidophyte Heterosigma akashiwo were studied, and the possible mechanisms were investigated through analyses of population growth dynamics, cellular ultrastructure and the physiological levels of $H$. akashiwo. The results showed that the inhibitory effect of LA on $H$. akashiwo cells increased with an increasing LA concentration. The levels of ROS and MDA were significantly elevated, indicating oxidative stress and lipid peroxidation due to LA exposure. At the same time, LA also activated the antioxidant system, including superoxide dismutase (SOD), catalase (CAT), and POD, and non-enzymatic antioxidants such as reduced AsA and glutathione (GSH). Transmission electron microscopy (TEM) revealed that the morphology of the algal cells was impaired in an LA-dependent manner. Annexin V-FITC/PI double staining and flow cytometric analysis revealed that LA exposure decreased the cellular mitochondrial membrane potential (MMP), increased the rate of apoptosis. LA modulated bcl-2/bax homeostasis and increased the expressions of cytochrome $c$ and caspases-3 and -9 , proving that LA induced cell death via the mitochondria-mediated apoptotic pathway. It was suggested that LA had allelopathic effects on $\mathrm{H}$. akashiwo, inducing physiological and morphological changes and finally triggering the apoptosis of $H$. akashiwo. All of these results showed that LA might have the potential as an algaecide to control harmful algae.

Keywords: harmful algal blooms (HABs), allelochemical, Heterosigma akashiwo, linoleic acid, oxidative damage

\section{INTRODUCTION}

Harmful algal blooms (HABs) as a kind of marine disaster (Anderson et al., 2008, 2012), have devastating impacts on fisheries, tourism, public health and ecosystems worldwide. In recent decades, increases in the severity, frequency and biogeographic range of these phenomena have occurred in many parts of the world (Anderson et al., 2012; Pichierri et al., 2017; Wells et al., 2015). 
The motile raphidophyte Heterosigma akashiwo is a globally distributed HAB-forming species (Smayda, 1998). As a eurythermic species, $H$. akashiwo can adapt well to the environment and has been found in red tide outbreaks in various countries such as the United States, Japan, and China (Khan et al., 1997; Rensel et al., 2010; Yang et al., 2021). Many blooms of $H$. akashiwo have been reported to be ichthyotoxic, resulting in the death of wild and farmed fish in coastal areas (Keppler et al., 2005; Ge et al., 2010). Relevant studies show that $H$. akashiwo may become the dominant species of red tide under the background of global climate change (Fu et al., 2008; Baek et al., 2017; Smit et al., 2021). In view of the harmfulness of H. akashiwo and the occurrence trend of algal bloom, controlling and eliminating $H$. akashiwo blooms has become an urgent worldwide problem.

Numerous regulating methods are currently applied to solve the problem of HAB mitigation, including traditional physical, chemical and biological technologies (Broekman et al., 2010; Chen and Pan, 2012; Mohamed et al., 2014), but secondary pollution, high costs or impractical problems are common (Zhang et al., 2013; Pal et al., 2020). Due to no secondary pollution, allelochemicals are considered to be environmentally friendly and effective biological algaecides (Backer et al., 2015; Harke et al., 2016; Eladel et al., 2019). To date, many allelochemicals identified from aquatic plants or algae display strong algicidal activity. For instance, the allelochemical ethyl 2methylacetoacetate (EMA) isolated from Phragmites communis Tris showed strong inhibitory activity against the growth of Microcystis aeruginosa and Chlorella pyrenoidosa ( $\mathrm{Li}$ and $\mathrm{Hu}$, 2005). Oh et al. (2010) isolated 5,8,11,14,17-eicosapentaenoic acid (EPA) from the extract of Corallina pilulifera, which had algicidal activity against the toxic dinoflagellate Cochlodinium polykrikoides. The inhibitory effect of allelochemicals is selective, which may be associated with the inhibitory mechanism. As biological algicides, allelochemicals have an influence on the physiological and biochemical properties of algae (Xue et al., 2018). Previous research indicated that allelochemicals might induce oxidative stress in algae, resulting in changes in cellular morphology, protein levels, antioxidant activities and cellular functions (Yu et al., 2019). The oxidation and antioxidation of organisms themselves are generally in dynamic equilibrium (Wrzaczek et al., 2013). When algal cells are exposed to various noxious stimuli, the quantity of reactive oxygen species (ROS) and free radicals increases, and their antioxidant defense systems can effectively scavenge these free radicals. However, once the concentration of allelochemicals is high enough to disrupt the balance, it may lead to oxidative damage or even the death of algal cells (Tan et al., 2019).

In our previous studies, linoleic acid (LA) was successfully extracted from Sargassum thunbergii and Corallina pilulifera, and it was found that LA significantly inhibited the population growth of Skeletonema costatum and Karenia mikimot, showing strong algicidal activity (Wang et al., 2012; Han et al., 2018). Although allelochemicals LA have been isolated from a variety of aquatic plants (Nakai et al., 2005; Alamsjah et al., 2008), the sensitivities of its allelopathic effects also vary among the different phytoplankton groups (Xue et al., 2018), and the mechanisms associated with their ability to inhibit targeted phytoplankton growth are also unknown. To date, the data on the physiological and morphological responses of algae to LA stress are very limited. Therefore, in the present study, the allelopathic effects of LA on the harmful microalga $H$. akashiwo, including growth inhibition, oxidant stress, ultrastructural changes and apoptosis, were explored. These physiological analyses could help elucidate the LA functional mechanisms associated with its inhibitory effects on algal growth.

\section{MATERIALS AND METHODS}

\section{Algal Culture and Chemicals}

$H$. akashiwo cultures were provided by the Algal Center of the Ocean University of China. The cultures were inoculated in f/2 medium (Guillard, 1975) prepared with sterile seawater. The algae were cultured at $25^{\circ} \mathrm{C}$ with cool white fluorescent light and $12 \mathrm{~h}: 12 \mathrm{~h}$ light-dark cycle conditions. Flasks were alternately disposed in the culture chamber, and the flasks were shaken twice a day to prevent wall growth and algal sedimentation. All followup experiments used exponential-phase algae at an initial cell density of $1 \times 10^{4}$ cells $/ \mathrm{mL}$.

LA (purity > 99\%, CAS number: 60-33-3) and acetone (purity $\geq 99.9 \%$, CAS number: 67-64-1) were purchased from Sigma-Aldrich (St. Louis, MO, United States), and the LA was dissolved in acetone to prepare a stock solution.

\section{Algal Growth Inhibition Assays}

LA dissolved in acetone was added to the algal cultures at exponential phase at final concentrations of 100, 300, 500, 700, and $900 \mu \mathrm{g} / \mathrm{L}$. Two controls were established in the experiments: a blank control (with sterile seawater) and solvent control (only containing $\leq 0.2 \%$ acetone). All of the above concentrations were applied in a growth inhibition assay for H. akashiwo. Every experiment was conducted in triplicate. The exposure experiments were performed for $72 \mathrm{~h}$, and the algal cell density was measured under an optical microscope at $0,24,48$ and $72 \mathrm{~h}$ postexposure with a hemocytometer. The inhibition rate was calculated according to OECD 201 (OECD, 1984).

\section{Transmission Electron Microscopy Observations}

Transmission Electron Microscopy (TEM) (JEM-1200EX, JEOL, Japan) was used to observe the cellular ultrastructure of the algae after 300, 500, and $700 \mu \mathrm{g} / \mathrm{L}$ LA exposure. After $48 \mathrm{~h}$ of exposure, the control and LA-treated cells were collected and fixed using a solution comprising 3.5\% glutaraldehyde in phosphate-buffered saline (PBS, $0.1 \mathrm{~mol} / \mathrm{L}, \mathrm{pH} 7.2$ ) and set at $4^{\circ} \mathrm{C}$ for 2 day. Then, the cells were postfixed in $1 \%$ osmic acid and washed 3 times with PBS. All treated samples were dehydrated in graded concentrations of ethanol, and then ultrathin sections were made for TEM observation. 


\section{Determinations of Reactive Oxygen Species and Lipid Peroxidation}

Determination of malondialdehyde (MDA) contents and the main ROS components, including superoxide anion $\left(\mathrm{O}_{2}{ }^{\bullet-}\right)$, hydrogen peroxide $\left(\mathrm{H}_{2} \mathrm{O}_{2}\right)$, hydroxyl radical $(\bullet \mathrm{OH})$. After $48 \mathrm{~h}$ of exposure to LA, the control and LA-treated cells were collected by centrifugation $(950 \times \mathrm{g})$ for $10 \mathrm{~min}$ at $4^{\circ} \mathrm{C}$. The harvested algal cells were suspended in PBS $(0.1 \mathrm{~mol} / \mathrm{L}, \mathrm{pH} 7.2)$ and immediately disrupted by ultrasonication (JY92-2D, Ningbo Scientiz Biotechnological Co., Ltd., China) for 2 min with a $1 \mathrm{~s}$ pause after each $1 \mathrm{~s}$ pulse in an ice bath. Then, the homogenate was centrifuged $\left(13,500 \times \mathrm{g}, 4^{\circ} \mathrm{C}\right)$ for $10 \mathrm{~min}$ to remove the cellular debris, and the supernatant was used to determine the intracellular $\mathrm{O}_{2}{ }^{\bullet-}, \mathrm{H}_{2} \mathrm{O}_{2}$ and $\bullet \mathrm{OH}$ levels and the MDA contents according to the manufacturer's instructions provided with the corresponding kits (Nanjing Jiancheng Bioengineering Institute, Nanjing, China). All of the parameters mentioned above were investigated on the basis of the total soluble protein, which was determined by the Bradford method (Bradford, 1976).

Detection of the total ROS levels. The fluorescent probe $2^{\prime} 7^{\prime}$-dichlorofluorescein diacetate (DCFH-DA, Beyotime Biotechnology Inc., Shanghai, China) was used to detect the intracellular total ROS levels. The control and LA-treated cells were separately centrifuged and collected and then resuspended in PBS $(0.1 \mathrm{~mol} / \mathrm{L}, \mathrm{pH} 7.2)$. The samples were mixed with DCFH$\mathrm{DA}$ and incubated at $37^{\circ} \mathrm{C}$ in the dark for $30 \mathrm{~min}$. After staining, the cells were resuspended in PBS, and their fluorescence intensity was detected by flow cytometry (FCM, Beckman Coulter, Fullerton, CA, United States) in the FL1 channel.

\section{Enzymatic Antioxidant and Non-enzymatic Antioxidant Assays}

Determination of the activities of antioxidant enzymes, including superoxide dismutase (SOD), catalase (CAT) and peroxidase (POD), and the contents of antioxidants, including ascorbic acid (AsA) and glutathione (GSH), in the algal cells was conducted after exposure to LA $(300,500$, and $700 \mu \mathrm{g} / \mathrm{L})$ for $48 \mathrm{~h}$. In brief, the control and LA-treated cells were sampled at $48 \mathrm{~h}$, and the supernatants were extracted according to the method described in section "Enzymatic Antioxidant and Nonenzymatic Antioxidant Assays." SOD activity was determined by the photochemical reduction of nitro blue tetrazolium (NBT) at $550 \mathrm{~nm}$ according to the method of Beauchamp and Fridovich (1971). CAT activity was assayed with a spectrophotometric method at $240 \mathrm{~nm}$ according to the method of Rao et al. (1996). POD activity was assayed with a guaiacol method at $470 \mathrm{~nm}$ according to the method of Rao et al. (1996). Similarly, the supernatant was used to determine the AsA and GSH contents according to the manufacturer's instructions provided with the corresponding kits (Nanjing Jiancheng Bioengineering Ins., Nanjing, China). The activity or the content of antioxidants were all calculated per mg of protein.

\section{Mitochondrial Membrane Potential Assays}

The Mitochondrial Membrane Potential (MMP) $(\Delta \psi \mathrm{m})$ was determined using the probe $5,5^{\prime}, 6,6^{\prime}$-tetrachloro- $1,1^{\prime}, 3,3^{\prime}$ - tetraethylbenzimidazole carbocyanide iodide (JC-1, Beyotime Biotechnology Inc., Shanghai, China). Based on the growth inhibition assay, we established one LA-treated group (500 $\mu \mathrm{g} / \mathrm{L}$ ), one blank control and one DMSO control. After exposure to LA for $48 \mathrm{~h}$, the algal cells were harvested, washed with PBS (0.1 mol/L, pH 7.2) and centrifuged at $950 \times \mathrm{g}$ for $10 \mathrm{~min}$. The supernatants were discarded, and the microalgae cells were stained with $\mathrm{JC}-1$ probes and incubated at $37^{\circ} \mathrm{C}$ in the dark for $20 \mathrm{~min}$. Then resuspended cells in PBS, and the fluorescence was detected by FCM in the FL-1 and FL-3 channels for the monomers and J-aggregates. Simultaneously, the stained cells were photographed using fluorescence microscopy (Nikon, Tokyo, Japan).

\section{Analysis of the Key Components of Apoptosis}

The LA concentration was set as described for the MMP experiment. Cells in the blank control, acetone control and LAtreated groups $(500 \mu \mathrm{g} / \mathrm{L})$ were centrifuged $(950 \times \mathrm{g}$ for $10 \mathrm{~min})$ and harvested after $48 \mathrm{~h}$ of exposure.

\section{Apoptosis Analysis}

The samples were stained with Annexin V-FITC and propidium iodide (PI) according to the manufacturer's instructions for the apoptosis detection kit (Beyotime Institute of Biotechnology of Shanghai, China). The stained cells were incubated for $20 \mathrm{~min}$ at $25^{\circ} \mathrm{C}$ in the dark. Then, the samples were detected by FCM in the FL-1 and FL-3 channels for FITC fluorescence and PI fluorescence.

\section{Detection of the Release of Cytochrome $c$}

The samples were analyzed according to the manufacturer's instructions with a Cytochrome $c$ assay kit (Nanjing Jiancheng Bioengineering Ins., Nanjing, China). The absorbance values were detected by a Synergy H1 microporous reader (BioTek. America) at $450 \mathrm{~nm}$.

\section{Detection of the Ratio of $\mathrm{Bax}$ to $\mathrm{Bcl}-2$}

The samples were analyzed according to the manufacturer's instructions for the Bcl-2 protein assay kit and Bcl-2 associated $\mathrm{x}$ protein (Bax) assay kit (Nanjing Jiancheng Bioengineering Ins., Nanjing, China). The absorbance values were detected by a Synergy H1 microporous reader (BioTek. America) at $450 \mathrm{~nm}$.

\section{Detection of the Caspase-3, -9 Activities}

The samples were analyzed according to the manufacturer's instructions of a caspase- 3 activity assay kit and caspase- 9 activity assay kit (Beyotime Biotechnology Inc., Shanghai, China). The absorbance values were detected by a Synergy H1 microporous reader (BioTek America) at $405 \mathrm{~nm}$.

\section{Data Analysis}

Data analysis was performed using SPSS v. 24.0, and the data were presented as the mean \pm standard deviation (SD). All experiments were independently repeated 3 times. The significance of each parameter was tested using one-way analysis of variance (ANOVA) followed by Tukey's multiple comparison test. For all analyses, differences were considered statistically 
significant when $p<0.05$. The correlation was analyzed using a Pearson test at $p<0.05$.

\section{RESULTS}

\section{Effect of Linoleic Acid on the Growth of Heterosigma akashiwo}

Figure 1A illustrates the ability of LA to inhibit the growth of $H$. akashiwo. Growth promotion of algal cells treated with LA was detected at low concentrations $(100 \mu \mathrm{g} / \mathrm{L})$. When exposed to LA in the concentration range of $300-900 \mu \mathrm{g} / \mathrm{L}$ for $72 \mathrm{~h}$, the cell density of $H$. akashiwo decreased in an LA-dependent manner. Moreover, the inhibition rate of algal cells significantly increased with an increasing LA concentration (Figure 1B), and the inhibition rate reached $97.3 \%$ when exposed to $900 \mu \mathrm{g} / \mathrm{L}$, which reached the highest value. These results indicated the inhibitory effects on the growth of $H$. akashiwo induced by LA exposure.

\section{Effects of Cellular Ultrastructure in Heterosigma akashiwo Cells Following Linoleic Acid Exposure}

TEM analysis revealed alterations in the internal ultrastructure of the $H$. akashiwo cells. In the blank control and acetone control (Figures 2A,B), the algal cells had an intact periplasm membrane, and the cell organelles, including chloroplasts and mitochondria, were uniformly distributed and maintained a normal ultrastructure. Specifically, the mitochondria had intact bilayer membranes and abundant cristae. However, after LA exposure for $48 \mathrm{~h}$, the cells appeared distinctly damaged (Figures 2C-E). Compared with the control, damage to the mitochondria of $H$. akashiwo was observed at $300 \mu \mathrm{g} / \mathrm{L}$, which was mainly manifested as a loss of mitochondrial inclusions, damage to the bilayer membrane, and blurring of the internal cristae (Figure 2C). Massive cell vacuolization appeared in the $500 \mu \mathrm{g} / \mathrm{L}$ LA-treated algal cells (Figure 2D). High concentrations of LA $(700 \mu \mathrm{g} / \mathrm{L})$ induced periplasm membrane fracture. Moreover, algal cell organelles such as chloroplasts and mitochondria disintegrated (Figure 2E).

\section{Effects of Linoleic Acid on Reactive Oxygen Species Production and Malondialdehyde Content in Heterosigma akashiwo}

In the present study, exposure to LA resulted in a remarkable increase in oxidative stress in the treated groups with respect to the control, causing a substantial increase $(p<0.05)$ in the intracellular ROS levels $\left(\mathrm{O}_{2}{ }^{-\bullet}, \bullet \mathrm{OH}, \mathrm{H}_{2} \mathrm{O}_{2}\right.$ and total ROS $)$. The $\mathrm{O}_{2}{ }^{-\bullet}$ levels sharply increased in the $500 \mu \mathrm{g} / \mathrm{L}$ group (Figure 3A), 4.8 times higher than the control $(p<0.05)$. In addition, the levels of $\bullet \mathrm{OH}, \mathrm{H}_{2} \mathrm{O}_{2}$ and total ROS were all increased in an LA-dependent manner (Figures 3B-D). Compared with the control, as the exposure concentration of LA increased, the MDA levels increased significantly and reached a maximum in the
$700 \mu \mathrm{g} / \mathrm{L}$ group $(p<0.05)$, which was 3.1 times that of the control (Figure 3E).

\section{Antioxidant System Response of Heterosigma akashiwo Cells to Linoleic Acid Exposure}

The SOD activity of the LA-treated group increased to the highest value at $300 \mu \mathrm{g} / \mathrm{L}$ (Figure 4A), which was obviously higher than that of the control group $(p<0.05)$, but remarkably decreased SOD activity was observed in the higher-dose LA-treated groups. With the increase in the activity in the LA-treated group, the CAT and POD activities showed different trends than SOD, and both reached the highest value in the $500 \mu \mathrm{g} / \mathrm{L}$ group (Figures 4B,C), while their activity decreased slightly at $900 \mu \mathrm{g} / \mathrm{L}$ but was still higher than that in the control $(p<0.05)$. The AsA content in the LA-treated groups increased dramatically at $300 \mu \mathrm{g} / \mathrm{L}$ and remained significantly higher than in the control with increasing concentrations of LA (Figure 4D). As shown in Figure 3E, a significant elevation in GSH content was observed after treatment with LA compared with the control, and the $500 \mu \mathrm{g} / \mathrm{L}$ group had the highest value.

\section{Analysis of the Key Components of Linoleic Acid-Induced Heterosigma akashiwo Cell Apoptosis}

The results of the Annexin V/PI analysis demonstrated that the number of apoptotic cells significantly increased in the LAtreated group compared with the control group (Figure 5A). Moreover, the apoptotic rate in the LA-treated group was markedly higher than that in the control group, with an approximately 4.25-fold increase (Figure 5B). These results suggest that LA at the concentration tested had a significant apoptotic effect on $H$. akashiwo cells.

After the cells were stained with JC-1, stronger green fluorescence was observed in cells treated with LA than in controls (Figure 6A). The percentage of JC-1 monomers in the LA-treated group also significantly increased $(p<0.05)$, approximately $67.7 \pm 0.13 \%$ higher than the control (Figure 6B). These results indicated that MMP was reduced, and the mitochondrial membrane was damaged in H. akashiwo cells.

The key components of the apoptosis pathway, i.e., cytochrome $c$, Bcl-2 protein family, caspase-3, and caspase- 9 , were detected. The results showed that the levels of cytochrome $c$ were significantly increased when exposed to LA $(p<0.05)$, which was approximately $72.6 \pm 0.14 \%$ higher than that of the control (Figure 6C). The activity of caspase-3 was dramatically increased, by approximately $52.1 \pm 0.7 \%$, in the LA-treated group. Similar significant increases were observed for caspase- 9 in the LA-treated group compared to the control (Figure 6D). The Bax to Bcl-2 ratios were simultaneously analyzed, and the results showed that the ratios of $\mathrm{Bax}$ to $\mathrm{Bcl}-2$ were elevated in the LA-treated group compared with the control (Figure 6E). These results suggest that LA may impair mitochondrial function and induce apoptosis through a mitochondrial-dependent pathway. 


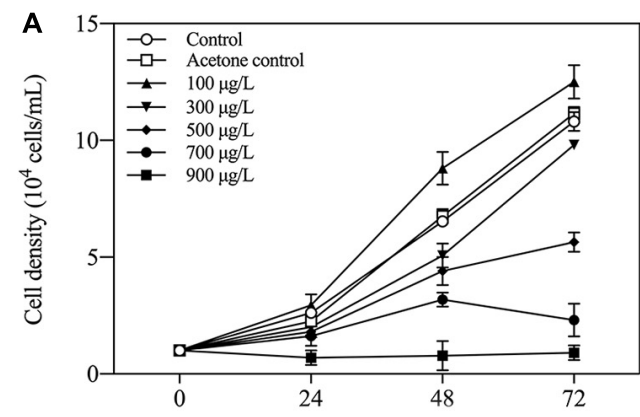

Exposure time (h)

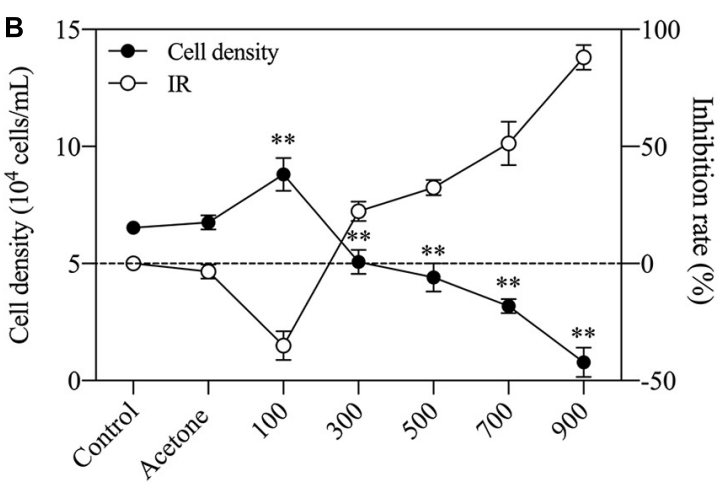

LA concentration $(\mu \mathrm{g} / \mathrm{L})$

FIGURE 1 | Changes in population growth in H. akashiwo exposed to LA. (A) Growth curves of $H$. akashiwo exposed to different concentrations of LA for 72 h. (B) Inhibition rate of $H$. akashiwo exposed to different concentrations of $L A$ after $48 \mathrm{~h}$ of exposure. The data are presented as the mean $\pm \mathrm{SD}(n=3)$. Asterisks indicate significant differences from acetone control (** indicate $p<0.01)$.

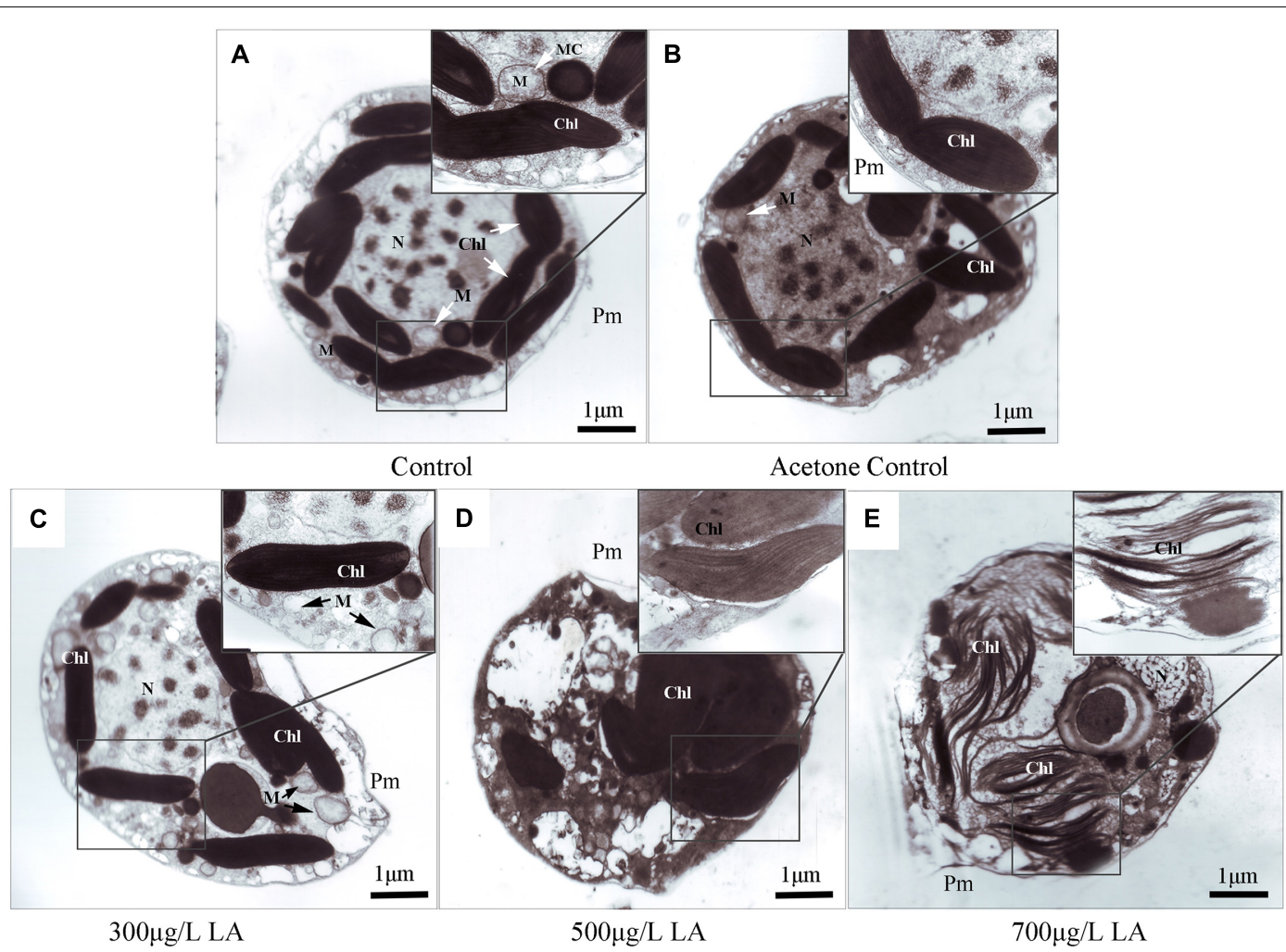

FIGURE 2 | Subcellular microstructure by TEM in the control and LA-treated groups of $H$. akashiwo: (A) control; (B) DMSO control; (C-E) different concentrations of LA-treated groups. Chl, M, MC, N, and Pm in each figure denote chloroplasts, mitochondria, mitochondrial cristae, nucleus and periplasm membranes, respectively.

\section{DISCUSSION}

The serious environmental and economic problems induced by HABs have led to great social concern (Lundgren et al., 2013; Lou and $\mathrm{Hu}, 2014)$. Although various methods have been proposed to control harmful algal growth, secondary pollution, high cost or impracticability constrain their application (Anderson, 1997; Hoko and Makado, 2011). The discovery of allelopathy provides a new dimension to solve this problem (Nakai et al., 2001). In aquatic ecosystems, allelopathic inhibition of microalgae by macrophytes is one of the main research fields in allelopathy (Qian et al., 2009). Fatty acids are widely found in seaweeds, and some fatty acids isolated from seaweed, including LA, tetradecanoic (TDA) and hexadecanoic acids (HAD), have been reported to have algae-inhibiting activity. In many studies, LA has shown the properties of high extraction and strong inhibition of 


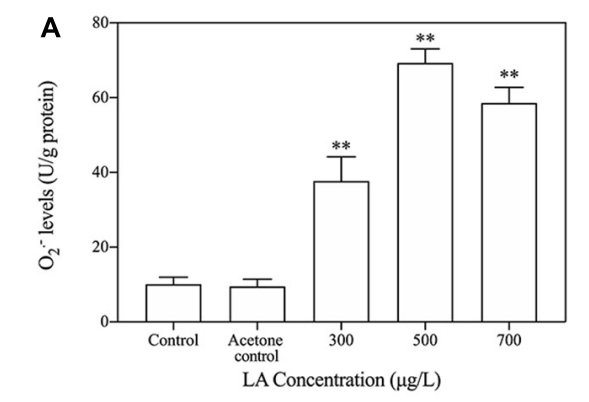

\section{D}

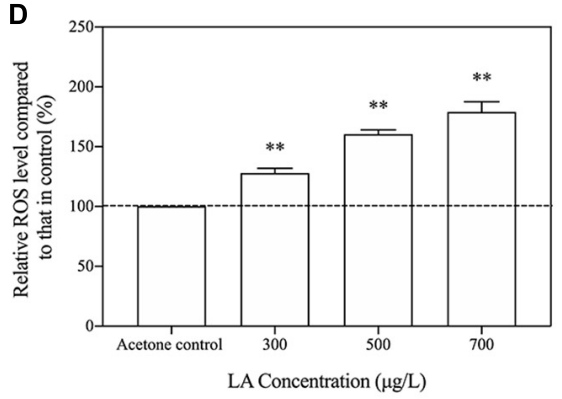

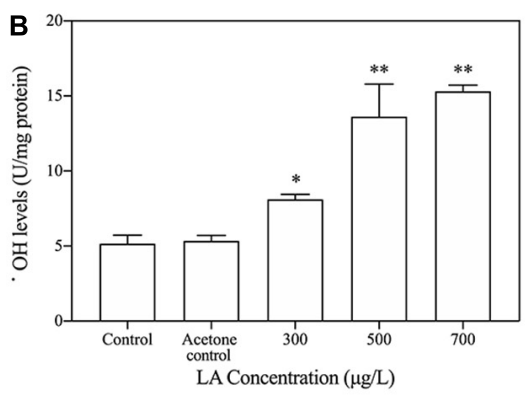

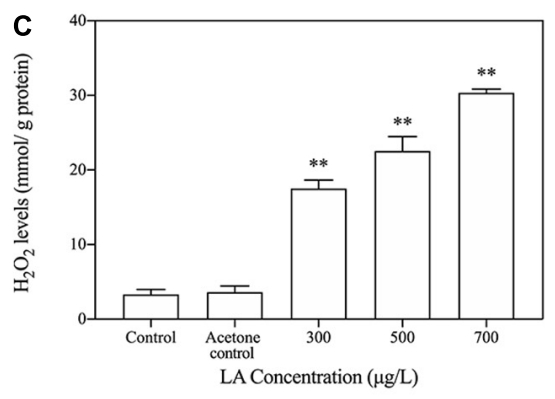

E

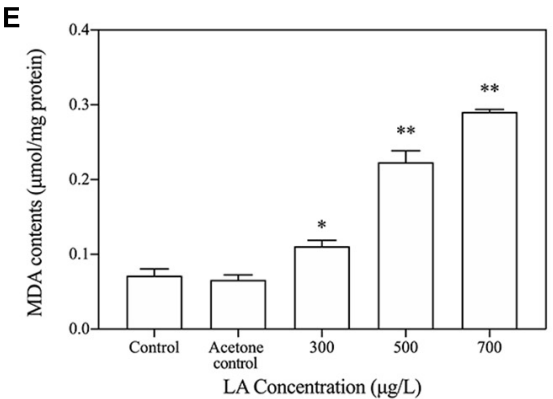

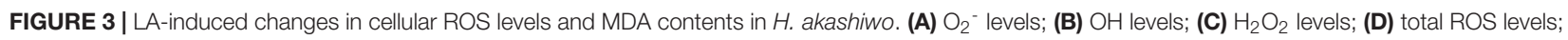
(E) MDA contents. The data are presented as the mean $\pm \mathrm{SD}(n=3)$. Asterisks indicate significant differences from acetone control $(*$ indicate $p<0.05$; ** indicate $p<0.01)$
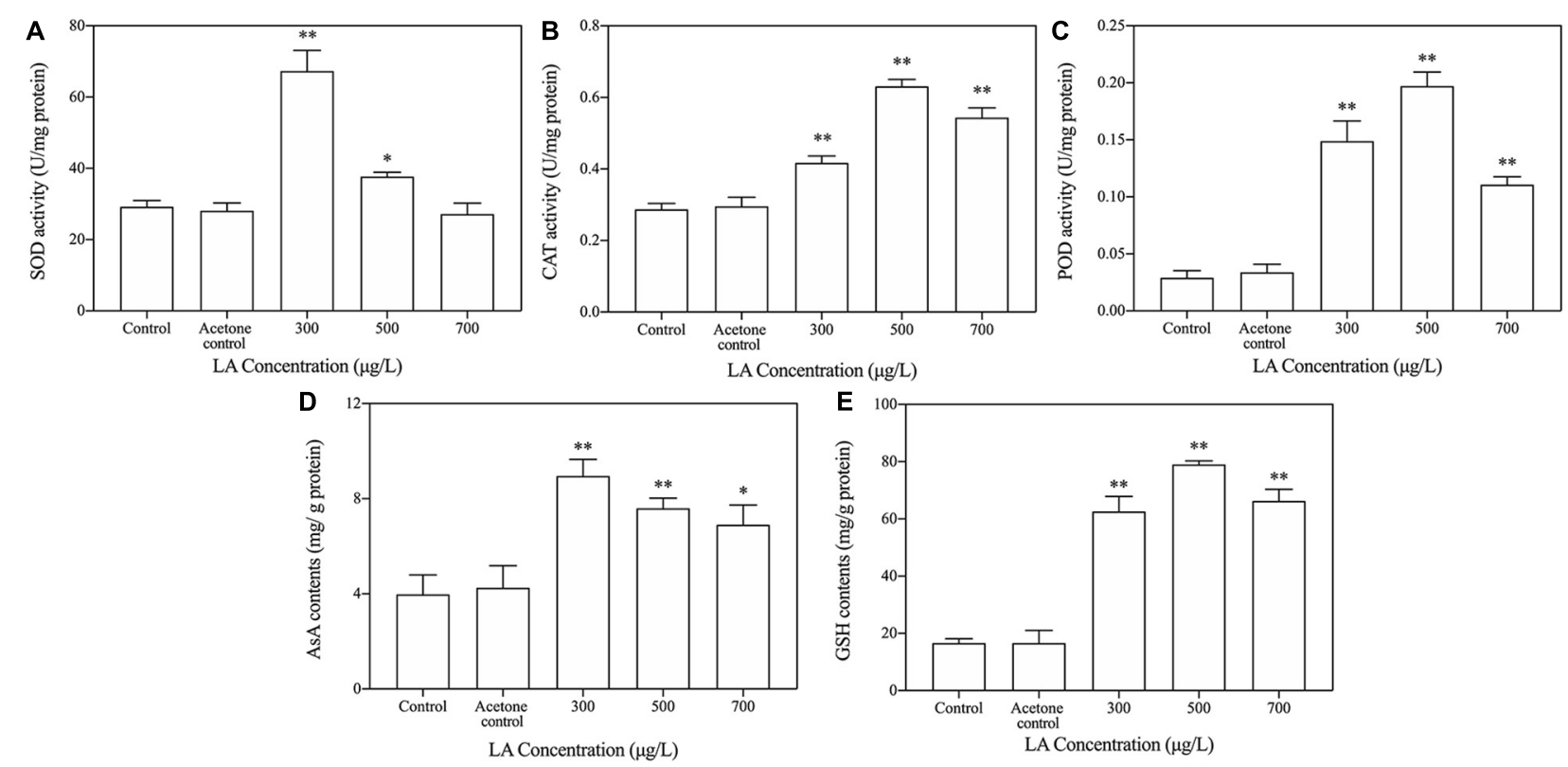

FIGURE 4 | Key enzymatic and non-enzymatic antioxidant responses to LA exposure in H. akashiwo. (A) SOD activities; (B) cat activities; (C) POD activities; (D) AsA contents; (E) GSH contents. The data are presented as the mean $\pm \mathrm{SD}(n=3)$. Asterisks indicate significant differences from acetone control (* indicate $p<0.05 ;{ }^{* *}$ indicate $\left.p<0.01\right)$.

microalgae (Hijano et al., 2021; Sun et al., 2021), which suggested that the number of the unsaturated double bond and the length of the carbon chain fatty acid are important structural element involved in the algal inhibition (Nakai et al., 2005; Zhang et al., 2009). Currently, there have been several studies on the modes of action of LA. To the best of our knowledge, most studies have focused on freshwater algae, such as Chlorella pyrenoidosa, Selenastrum capricornutum, and Microcystis aeruginosa (Kamaya et al., 2003; DellaGreca et al., 2010; Song et al., 2017), but the potential mechanisms of LA against marine HABs have not been 


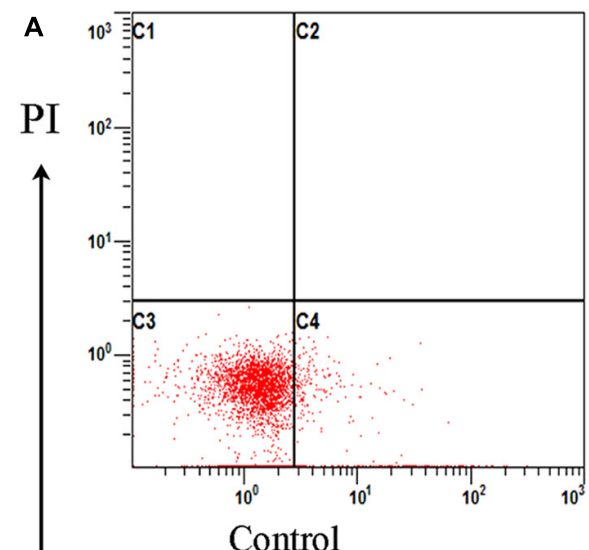

Control
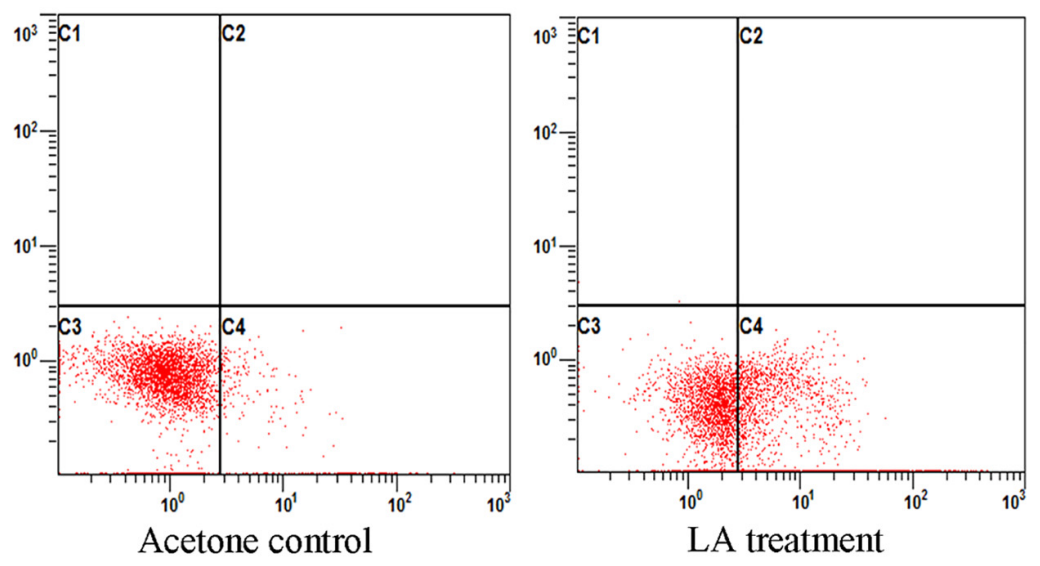

Annexin V-FITC

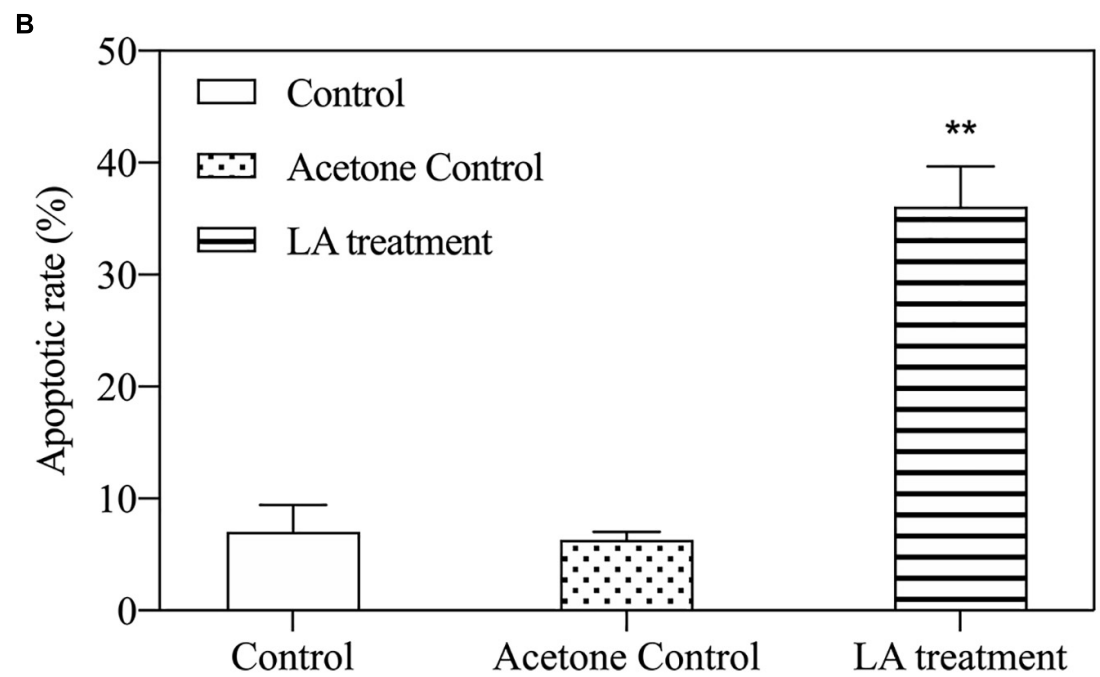

FIGURE 5 | Apoptosis of $H$. akashiwo cells treated with LA. (A) Representative flow-cytometric analysis of apoptosis. (B) Percentages of apoptotic cells by flow cytometry. The data are presented as the mean $\operatorname{SD}(n=3)$. Asterisks indicate significant differences from acetone control $(* *$ indicate $p<0.01)$.

fully elucidated. Hence, the investigation of the mode of action of LA against $H$. akashiwo in this study might help to further explore why inhibition occurs and the role of LA in the field of algal bloom control.

Our results indicated that the inhibitory effect of LA on $H$. akashiwo increased with an increasing concentration. The inhibition rate is a common parameter used to quantify allopathic effects (Nakai et al., 1999). Obviously, the inhibition rate was increased in an LA concentration-dependent manner (Figure 1B). It should be noted that while the $H$. akashiwo cells were significantly inhibited by LA, the effect in the marine microalgae was complex, with stimulation of algal growth at a relatively low LA concentration $(100 \mu \mathrm{g} / \mathrm{L})$ and a significant inhibition at the higher concentrations tested. LA had a concentration effect of "promotion at a low concentration and inhibition at a high concentration" on $H$. akashiwo, which is consistent with previous results (Calabrese, 2008; Qian et al., 2019). The reason for this effect might be that a low concentration of LA could increase the permeability of the algal cell membrane by increasing the enzyme activity of algal cells (Karasyova et al., 2007). LA (above $300 \mu \mathrm{g} / \mathrm{L}$ ) significantly inhibited the growth of algae, and the reason for this might be that when the allelochemicals contained in LA exceeded the acceptable range of algal cells, the algal antioxidant enzyme system and cell membrane were increasingly damaged (Mecina et al., 2017). Inhibition of growth could be induced by damage to the cell membranes and organelles of the algal ( $\mathrm{Gu}$ et al., 2017). After LA exposure for $48 \mathrm{~h}$, the cells appeared to be distinctly damaged, including cell vacuolization and disintegration of algal cell organelles such as the chloroplast and mitochondria (Figures 2D,E). Consequently, damage to algal organelles may inhibit the growth of algae, with damage to chloroplasts and mitochondria in particular leading to oxidative stress.

LA causes oxidative stress, which produces a large amount of ROS by changing intracellular antioxidant enzymes activities and inducing lipid peroxidation (Song et al., 2017; Han et al., 2018; 
A

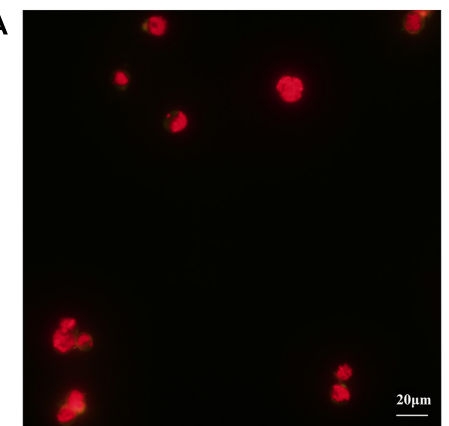

Control

B

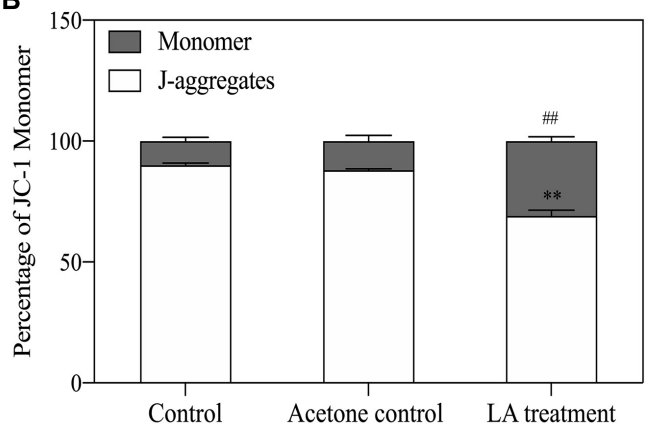

D

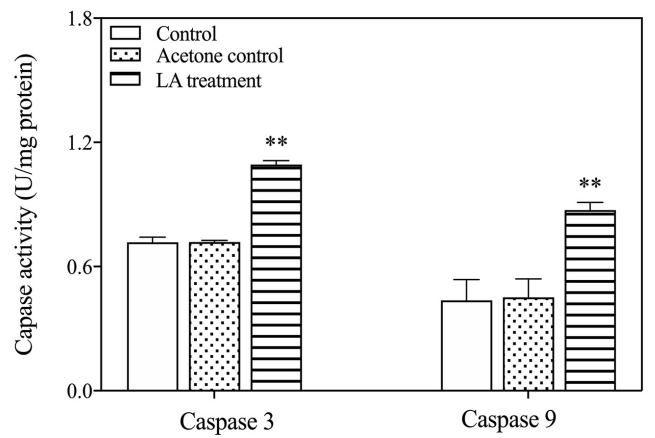

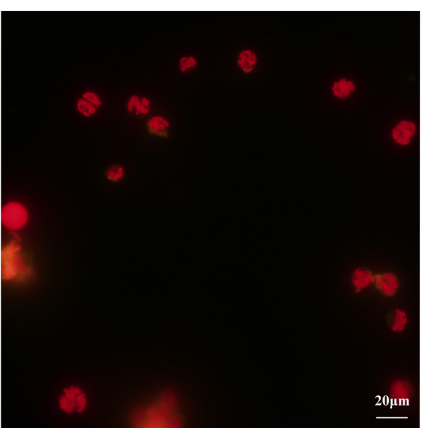

Acetone Control

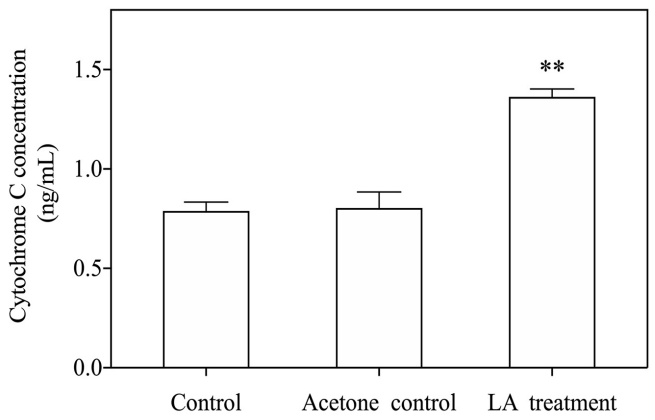

E

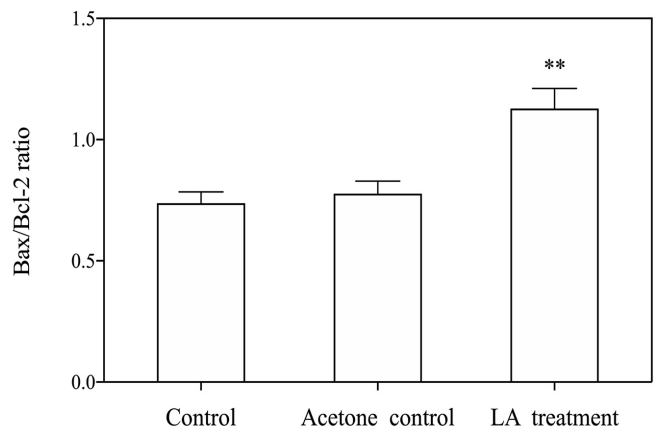

FIGURE 6 | Key components of LA-induced $H$. akashiwo cell apoptosis through the mitochondria-dependent pathway. (A) Fluorescence changes in stained cells by a fluorescence microscope. Red and green fluorescence indicates the normal and abnormal state of cell membrane potential, respectively. (B) Percentages of JC-1 monomers and J-aggregates. (C) Changes in the cytochrome c levels. (D) Changes in the Bax to Bcl-2 ratios. (E) Changes in the caspase-9 and caspase-3 activities. The data are presented as the mean $\pm \operatorname{SD}(n=3)$. ** and \#\# indicate $p<0.01$ relative to the acetone control.

Guo et al., 2015; Qian et al., 2018). In this study, the total ROS level increased, and the levels of different ROS species include $\mathrm{O}_{2}{ }^{\bullet-}, \mathrm{H}_{2} \mathrm{O}_{2}$ and $\mathrm{OH}$ simultaneously increased in algal cells after LA exposure (Figures 3A-D), indicating that LA induces excessive ROS in $H$. akashiwo cells. To scavenge ROS and avoid oxidative damage, algal cells possess a set of cellular defense systems mediated via enzymes and non-enzymatic antioxidants (Morales et al., 2004; Yang et al., 2013). SOD plays a central role in the defense against oxidative stress and catalyzes the dismutation of $\mathrm{O}_{2}{ }^{\bullet-}$ to $\mathrm{H}_{2} \mathrm{O}_{2}$ (del Río et al., 2018). Analogous to SOD, CAT and POD are also important enzymes with the ability to catalyze the decomposition of hydrogen peroxide in resistance to oxidation damage caused by ROS (Xia et al., 2015; Hua et al., 2018). In the present study, SOD was induced by LA in the early stages to resist stress, which is consistent with previous research
(Hou et al., 2019). Then, the activities of SOD decreased with an increasing LA concentration, and the contents of POD and CAT also went through a process of induction and suppression, which indicated that LA could abate or impair the antioxidant defense system and therefore exhibited a strong algal inhibiting ability.

AsA and GSH also play a preponderant role in the cell redox balance and metabolic regulation. In our study, the sharp increases in AsA and GSH at $300 \mu \mathrm{g} / \mathrm{L}$ LA hinted that the production of $\mathrm{H}_{2} \mathrm{O}_{2}$ was elevated and that AsA and GSH were actively involved in the antioxidant response to oxidative stress when exposed to LA at low concentrations (Chen et al., 2015). However, the ROS increased dramatically, and oxidative stress was induced as the antioxidant defense system was insufficient to scavenge all ROS, triggering defense system collapse. To clarify whether oxidative stress caused 
oxidative harm to $H$. akashiwo, membrane lipid peroxidation was evaluated. MDA was commonly used as a biomarker to estimate oxidative damage in cells (Hua et al., 2018; Liu et al., 2019). Markedly increases in MDA content combined with the changes in cellular ultrastructure, indicated that LA might have induced lipid peroxidation and damaged the $H$. akashiwo cell membranes.

The overproduction of ROS is an important factor involved in cellular apoptosis (Nobel et al., 2000; Calamita et al., 2005). In the present study, flow cytometry and morphological changes indicated that apoptosis occurred quickly after LA exposure in $H$. akashiwo (Figure 5). Indeed, as the location where most intracellular ROS are produced, mitochondria are at a cross-point in the signaling pathways involving ROS, especially those concerning apoptosis (Jones, 2000). In addition, MMP is involved in a number of cellular functions and plays a central role in apoptosis by integrating death signals (Brenner and Kroemer, 2000; Lee et al., 2004). In our experiment, MMP in the algae decreased when exposed to LA (Figures 6A,B), which indicated that LA might lead to a significant decrease in MMP and trigger apoptosis in algae. In the present study, as the key components in triggering and regulating apoptosis by the mitochondrial pathway, the cytochrome $c, \mathrm{Bcl}-2$ protein family, caspase- 9 and caspase- 3 showed significant changes following LA exposure. As an essential component of the mitochondrial respiratory chain, cytochrome $c$ released from mitochondria to the cytosol has been demonstrated to be a crucial step in the activation of apoptosis (Moriya et al., 2000; Redza-Dutordoir and Averill-Bates, 2016). In addition, previous studies have shown that the Bcl-2 protein family, which regulates mitochondrial function, is related to apoptosis sensitivity. Among these proteins, the Bax to $\mathrm{Bcl}-2$ ratio is vital to induce permeabilization of the outer mitochondrial membrane and the release of cytochrome $c$, leading to the activation of caspases (Bras et al., 2005; Moll et al., 2005). Therefore, we considered that the excessive production of ROS induced by LA might be the key factor in the collapse of the MMP, followed by disturbances in the $\mathrm{Bax}$ to $\mathrm{Bcl}-2$ ratio, concomitant with cytochrome $c$ combining with caspase- 9 after its release from the mitochondria, and thus activating downstream caspase- 3 to initiate apoptosis.

\section{CONCLUSION}

Through the analysis of these physiological indexes, the inhibitory mechanism of LA on $H$. akashiwo growth was

\section{REFERENCES}

Alamsjah, M. A., Hirao, S., Ishibashi, F., Oda, T., and Fujita, Y. (2008). Algicidal activity of polyunsaturated fatty acids derived from Ulva fasciata and U. pertusa (Ulvaceae, Chlorophyta) on phytoplankton. J. Appl. Phycol. 20, 713-720. doi: 10.1007/s10811-007-9257-5

Anderson, D. M. (1997). Turning back the harmful red tide. Nature 388, 513-514. doi: $10.1038 / 41415$

Anderson, D. M., Burkholder, J. M., Cochlan, W. P., Glibert, P. M., Gobler, C. J., Heil, C. A., et al. (2008). Harmful algal blooms and eutrophication: examining explored. The results demonstrated that the decrease in algal density was directly related to the activity of the antioxidant system of algal cells. LA-induced overproduction of ROS caused oxidative stress in $H$. akashiwo cells, with lipid peroxidation, compromising membrane integrity and seriously impairing mitochondrial function, resulting in growth inhibition. In addition, upon further increases in ROS generation, cytochrome $c$ was released concomitantly with activation of caspase- 3 and a loss of mitochondrial membrane potential, eventually leading to apoptosis through the mitochondrial pathway. These results show that LA may be an eco-friendly alternative for use in the control of harmful blooms in aquatic ecosystems.

\section{DATA AVAILABILITY STATEMENT}

The raw data supporting the conclusions of this article will be made available by the authors, without undue reservation.

\section{AUTHOR CONTRIBUTIONS}

RW conceived and supervised the project. QL and RW conceived and designed the experiments. QL performed the experiments and analyzed the data, and wrote the manuscript. The final manuscript, figures, and tables were revised by RW with input from QL. Both authors participated in the discussions of the results and the preparation of the manuscript and contributed to the article and approved the submitted version.

\section{FUNDING}

This work was supported by National Natural Science Foundation of China (Grant No. 31971503).

\section{ACKNOWLEDGMENTS}

We thank the Marine Ecology Laboratory in the College of Marine Life Sciences, Ocean University of China for providing the $H$. akashiwo strain. We were also thankful to all the members in the lab for their assistance.

linkages from selected coastal regions of the United States. Harmful Algae 8, 39-53. doi: 10.1016/j.hal.2008.08.017

Anderson, D. M., Cembella, A. D., and Hallegraeff, G. M. (2012). Progress in understanding harmful algal blooms: paradigm shifts and new technologies for research, monitoring, and management. Annu. Rev. Mar. Sci. 4, 143-176. doi: 10.1146/annurev-marine-120308-081121

Backer, L. C., Manassaram-Baptiste, D., LePrell, R., and Bolton, B. (2015). Cyanobacteria and algae blooms: review of health and environmental data from the harmful algal bloom-related illness surveillance system surveillance system (HABISS) 2007-2011. Toxins 7, 1048-1064. doi: 10.3390/toxins7041048 
Baek, S. H., Lee, M. J., and Kim, Y. B. (2017). Spring phytoplankton community response to an episodic windstorm event in oligotrophic waters offshore from the Ulleungdo and Dokdo islands. Korea. J. Sea Res. 132, 1-14. doi: 10.1016/j. seares.2017.11.003

Beauchamp, C., and Fridovich, I. (1971). Superoxide dismutase: improved assays and an assay applicable to acrylamide gels. Anal. Biochem. 44, 276-287. doi: 10.1016/0003-2697(71)90370-8

Bradford, M. M. (1976). A rapid and sensitive method for the quantitation of microgram quantities of protein utilizing the principle of protein-dye binding. Anal. Biochem. 72, 248-254. doi: 10.1016/0003-2697(76)90527-3

Bras, M., Queenan, B., and Susin, S. A. (2005). Programmed cell death via mitochondria: different modes of dying. Biochemistry 70, 231-239. doi: 10.1007/ s10541-005-0105-4

Brenner, C., and Kroemer, G. (2000). Apoptosis. Mitochondria-the death signal integrators. Science 289, 1150-1151. doi: 10.1126/science.289.5482.1150

Broekman, S., Pohlmann, O., Beardwood, E. S., and Meulenaer, E. C. D. (2010). Ultrasonic treatment for microbiological control of water systems. Ultrason. Sonochem. 17, 1041-1048. doi: 10.1016/j.ultsonch.2009.11.011

Calabrese, E. J. (2008). Hormesis: why it is important to toxicology and toxicologists. Environ. Toxicol. Chem. 27, 1451-1474. doi: 10.1897/07-541.1

Calamita, G., Ferri, D., Gena, P., Liquori, G. E., Cavalier, A., Thomas, D., et al. (2005). The inner mitochondrial membrane has aquaporin-8 water channels and is highly permeable to water. J. Biol. Chem. 280, 17149-17153. doi: 10.1074/ jbc.C400595200

Chen, J., and Pan, G. (2012). Harmful algal blooms mitigation using clay/soil/sand modified with xanthan and calcium hydroxide. J. Appl. Phycol. 24, 1183-1189. doi: 10.1007/s10811-011-9751-7

Chen, L., Mao, F., Kirumba, G. C., Jiang, C., Manefield, M., and He, Y. (2015). Changes in metabolites, antioxidant system, and gene expression in Microcystis aeruginosa under sodium chloride stress. Ecotox. Environ. Safe. 122, 126-135. doi: 10.1016/j.ecoenv.2015.07.011

del Río, L. A., Corpas, F. J., López-Huertas, E., and Palma, J. (2018). "Plant superoxide dismutases: function under abiotic stress conditions," in Antioxidants and Antioxidant Enzymes in Higher Plants, ed. Gupta (Cham: Springer), 1-26. doi: 10.1007/978-3-319-75088-0_1

DellaGreca, M., Zarrelli, A., Fergola, P., Cerasuolo, M., Pollio, A., and Pinto, G. (2010). Fatty acids released by Chlorella vulgaris and their role in interference with Pseudokirchneriella subcapitata: experiments and modelling. J. Chem. Ecol. 36, 339-349. doi: 10.1007/s10886-010-9753-y

Eladel, H., Battah, M., Dawa, A., Abd-Elhay, R., and Anees, D. (2019). Effect of rice straw extracts on growth of two phytoplankton isolated from a fish pond. J. Appl. Phycol. 31, 557-553. doi: 10.1007/s10811-019-01766-0

Fu, F. X., Zhang, Y., Warner, M. E., Feng, Y., Sun, J., and Hutchins, D. A. (2008). A comparison of future increased $\mathrm{CO}_{2}$ and temperature effects on sympatric Heterosigma akashiwo and Prorocentrum minimum. Harmful Algae 7, 76-90. doi: 10.1016/j.hal.2007.05.006

Ge, W., Wang, J. F., and Chai, C. (2010). Detection of hemolytic activity of toxin in Heterosigma akashiwo. Mar. Environ. Sci. 29, 747-750. doi: 10.1631/jzus. A1000244

Gu, S., Zheng, H., Xu, Q., Sun, C., Shi, M., Wang, Z., et al. (2017). Comparative toxicity of the plasticizer dibutyl phthalate to two freshwater algae. Aquat. Toxicol. 191, 122-130. doi: 10.1016/j.aquatox.2017.08.007

Guillard, R. R. L. (1975). "Culture of phytoplankton for feeding marine invertebrates," in Culture of Marine Invertebrate Animals, eds W. L. Smith and M. H. Chanley (Boston, MA: Springer), 29-60. doi: 10.1007/978-1-4615-87149_3

Guo, P., Liu, Y., and Liu, C. (2015). Effects of chitosan, gallic acid, and algicide on the physiological and biochemical properties of Microcystis flos-aquae. Environ. Sci. Pollut. Res. Int. 22, 13514-13521. doi: 10.1007/s11356-0154500-0

Han, M., Wang, R., Ding, N., Liu, X., Zheng, N., Fu, B., et al. (2018). Reactive oxygen species-mediated caspase- 3 pathway involved in cell apoptosis of Karenia mikimotoi induced by linoleic acid. Algal Res. 36, 48-56. doi: 10.1016/ j.algal.2018.10.013

Harke, M. J., Steffen, M. M., Gobler, C. J., Otten, T. G., Wilhelm, S. W., Wood, S. A., et al. (2016). A review of the global ecology, genomics, and biogeography of the toxic cyanobacterium. Microcystis spp. Harmful Algae 54, 4-20. doi: 10.1016/j.hal.2015.12.007
Hijano, N., Nepomuceno, M., Cantrell, C., Duke, S. O., and Alves, P. L. C. A. (2021). Characterization of the Allelopathic Potential of Sugarcane Leaves and Roots. J. Agricult. Chem. Env. 10, 257-274. doi: 10 4236/jacen.2021.103016

Hoko, Z., and Makado, P. K. (2011). Optimization of algal removal process at Morton Jaffray water works, Harare, Zimbabwe. Phys. Chem. Earth 36, 1141-1150. doi: 10.1016/j.pce.2011.07.074

Hou, X., Huang, J., Tang, J., Wang, N., Zhang, L., Gu, L., et al. (2019). Allelopathic inhibition of juglone (5-hydroxy-1,4-naphthoquinone) on the growth and physiological performance in Microcystis aeruginosa. J. Environ. Manage. 232, 382-386. doi: 10.1016/j.jenvman.2018.11.105

Hua, Q., Liu, Y., Yan, Z., Zeng, G. M., Liu, S. B., Wang, W. J., et al. (2018). Allelopathic effect of the rice straw aqueous extract on the growth of Microcystis aeruginosa. Ecotox. Environ. Safe. 148, 953-959. doi: 10.1016/j.ecoenv.2017.11. 049

Jones, A. (2000). Does the plant mitochondrion integrate cellular stress and regulate programmed cell death? Trends Plant Sci. 5, 225-230. doi: 10.1016/ S1360-1385(00)01605-8

Kamaya, Y., Kurogi, Y., and Suzuki, K. (2003). Acute toxicity of fatty acids to the freshwater green alga Selenastrum capricornutum. Environ. Toxicol. 18, 289-294. doi: 10.1002/tox.10127

Karasyova, T. A., Klose, E. O., Menzel, R., and Steinberg, C. E. W. (2007). Natural organic matter differently modulates growth of two closely related coccal green algal species. Environ. Sci. Pollut. Res. Int. 14, 88-93. doi: 10.1065/espr2006.06. 317

Keppler, C. J., Hoguet, J., Smith, K., Ringwood, A. H., and Lewitus, A. J. (2005). Sublethal effects of the toxic alga Heterosigma akashiwo on the southeastern oyster (Crassostrea virginica). Harmful Algae 4, 275-285. doi: 10.1016/j.hal. 2004.05.002

Khan, S., Arakawa, O., and Onoue, Y. (1997). Neurotoxins in a toxic red tide of Heterosigma akashiwo (Raphidophyceae) in Kagoshima bay. Japan. Aquac. Res. 28, 9-14. doi: 10.1046/j.1365-2109.1997.t01-1-00823.x

Lee, Y. J., Jeong, S. Y., Karbowski, M., Smith, C. L., and Youle, R. J. (2004). Roles of the mammalian mitochondrial fission and fusion mediators Fis1, Drp1, and Opa1 in apoptosis. Mol. Biol. Cell 15, 5001-5011. doi: 10.1091/mbc.E04-040294

Li, F. M., and Hu, H. Y. (2005). Isolation and characterization of a novel antialgal allelochemical from Phragmites communis. Appl. Environ. Microb. 71, 65456553. doi: $10.1017 / \mathrm{S} 0263574709005426$

Liu, Q., Tang, X., Wang, Y., Yang, Y., Zhang, W., Zhao, Y., et al. (2019). ROS changes are responsible for tributyl phosphate (TBP)-induced toxicity in the alga Phaeodactylum tricornutum. Aquat. Toxicol. 208, 168-178. doi: 10.1016/j. aquatox.2019.01.012

Lou, X., and Hu, C. (2014). Diurnal changes of a harmful algal bloom in the East China Sea: Observations from GOCI. Remote Sens. Environ. 140, 562-572. doi: $10.1016 /$ j.rse.2013.09.031

Lundgren, V. M., Roelke, D. L., Grover, J. P., Brooks, B. W., Prosser, K. N., Scott, W. C., et al. (2013). Interplay between ambient surface water mixing and manipulated hydraulic flushing: Implications for harmful algal bloom mitigation. Ecol. Eng. 60, 289-298. doi: 10.1016/j.ecoleng.2013.07.063

Mecina, G. F., Dokkedal, A. L., Saldanha, L. L., Chia, M. A., Cordeiro-Araújoe, M. K., Bittencourt-Oliveira, M. C., et al. (2017). Response of Microcystis aeruginosa BCCUSP 232 to barley (Hordeum vulgare L.) straw degradation extract and fractions. Sci. Total Environ. 599-600, 1837-1847. doi: 10.1016/j. scitotenv.2017.05.156

Mohamed, Z. A., Hashem, M., and Alamri, S. A. (2014). Growth inhibition of the cyanobacterium Microcystis aeruginosa and degradation of its microcystin toxins by the fungus Trichoderma citrinoviride. Toxicon 86, 51-58. doi: 10.1016/ j.toxicon.2014.05.008

Moll, U. M., Wolff, S., Speidel, D., and Deppert, W. (2005). Transcriptionindependent pro-apoptotic functions of p53. Curr. Opin. Cell Biol. 17, 631-636. doi: 10.1016/j.ceb.2005.09.007

Morales, A. E., Pérez-Jiménez, A., Hidalgo, M. C., Abellán, E., Cardenete, G. (2004). Oxidative stress and antioxidant defenses after prolonged starvation in Dentex dentex liver. Toxicol. Pharm. 139, 153-161. doi: 10.1016/j.cca.2004. 10.008

Moriya, R., Uehara, T., and Nomura, Y. (2000). Mechanism of nitric oxide-induced apoptosis in human neuroblastoma SH-SY5Y cells. Febs Lett. 484, 253-260. doi: $10.1016 /$ S0014-5793(00)02167-0 
Nakai, S., Inoue, Y., and Hosomi, M. (2001). Algal growth inhibition effects and inducement modes by plant-producing phenols. Water Res. 35, 1855-1859. doi: 10.1016/S0043-1354(00)00444-9

Nakai, S., Inoue, Y., Hosomi, M., and Murakami, A. (1999). Growth inhibition of blue-green algae by allelopathic effects of macrophytes. Water Sci. Technol. 39, 47-53. doi: 10.2521/jswtb.33.215

Nakai, S., Yamada, S., and Hosomi, M. (2005). Anti-cyanobacterial fatty acids released from Myriophyllum spicatum. Hydrobiologia 543, 71-78. doi: 10.1007/ s10750-004-6822-7

Nobel, C. S. I., Aronson, J. K., van den Dobbelsteen, D. J., and Slater, A. F. G. (2000). Inhibition of $\mathrm{Na}^{+} / \mathrm{K}^{+}$-ATPase may be one mechanism contributing to potassium efflux and cell shrinkage in CD95-induced apoptosis. Apoptosis 5, 153-163. doi: 10.1023/A:1009684713784

OECD (1984). Algal growth inhibition test. OECD Guidelines for Testing of Chemicals 201. Paris: Organisation for Economic Cooperation and Development.

Oh, M. Y., Lee, S. B., Jin, D. H., Hong, Y. K., and Jin, H. J. (2010). Isolation of algicidal compounds from the red alga Corallina pilulifera against red tide microalgae. J. Appl. Phycol. 22, 453-458. doi: 10.1007/s10811-009-9478-x

Pal, M., Yesankar, P. J., Dwivedi, A., and Qureshi, A. (2020). Biotic control of harmful algal blooms (HABs): A brief review. J. Environ. Manage. 268:110687. doi: 10.1016/j.jenvman.2020.110687

Pichierri, S., Accoroni, S., Pezzolesi, L., Guerrini, F., Romagnoli, T., Pistocchi, R., et al. (2017). Allelopathic effects of diatom filtrates on the toxic benthic dinoflagellate Ostreopsis cf. ovata. Mar. Environ. Res. 131, 116-122. doi: 10. 1016/j.marenvres.2017.09.016

Qian, H., Xu, J., Tao, L., Qi, Z., Qian, Q., Yang, Z., et al. (2018). Responses of unicellular alga Chlorella pyrenoidosa to allelochemical linoleic acid. Sci. Total Environ. 625, 1415-1422. doi: 10.1016/j.scitotenv.2018.01.053

Qian, Y. P., Li, X. T., and Tian, R. N. (2019). Effects of aqueous extracts from the rhizome of Pontederia cordata on the growth and interspecific competition of two algal species. Ecotox. Environ. Safe. 168, 401-407. doi: 10.1016/j.ecoenv. 2018.10.086

Qian, H., Xu, X., Wei, C., Jiang, H., Jin, Y., Liu, W., et al. (2009). Allelochemical stress causes oxidative damage and inhibition of photosynthesis in Chlorella vulgaris. Chemosphere 75, 368-375. doi: 10.1016/j.chemosphere.2008.12.040

Rao, M. V., Paliyath, G., and Ormrod, D. P. (1996). Ultraviolet-B and Ozoneinduced biochemical changes in antioxidant enzymes of Arabidopsis thaliana. Plant Physiol. 110, 125-136. doi: 10.1104/pp.110.1.125

Redza-Dutordoir, M., and Averill-Bates, D. A. (2016). Activation of apoptosis signalling pathways by reactive oxygen species. Mole. Cell Res. 1863, 2977-2992. doi: 10.1016/j.bbamcr.2016.09.012

Rensel, J. E., Haigh, N., and Tynan, T. J. (2010). Fraser river sockeye salmon marine survival decline and harmful blooms of Heterosigma akashiwo. Harmful Algae 10, 98-115. doi: 10.1016/j.hal.2010.07.005

Smayda, T. J. (1998). "Ecophysiology and bloom dynamics of Heterosigma akashiwo (Raphidophyceae)," in Physiological Ecology of Harmful Algal Blooms, eds D. M. Anderson, A. D. Cembella, and G. M. Hallegraef (Heidelberg: Springer Verlag), 113-132.

Smit, T., Lemley, D. A., Adams, J. B., and Strydom, N. A. (2021). Preliminary insights on the fine-scale responses in larval Gilchristella aestuaria (Family Clupeidae) and dominant zooplankton to estuarine harmful algal blooms. Estuar. Coast. Shelf S. 249:107072. doi: 10.1016/j.ecss.2020.107072

Song, H., Lavoie, M., Fan, X., Tan, H., Liu, G., Xu, P., et al. (2017). Allelopathic interactions of linoleic acid and nitric oxide increase the competitive ability of Microcystis aeruginosa. Isme J. 11, 1865-1876. doi: 10.1038/ismej.2017.45

Sun, S., Hu, S., Zhang, B., Sun, X., and Xu, N. (2021). Allelopathic effects and potential allelochemical of Sargassum fusiforme on red tide microalgae
Heterosigma akashiwo. Mar. Pollut. Bull. 170:112673. doi: 10.1016/j.marpolbul. 2021.112673

Tan, K., Huang, Z., Ji, R., Qiu, Y., and Liu, J. (2019). A review of allelopathy on microalgae. Microbiology 165, 587-592. doi: 10.1099/mic.0.000776

Wang, R., Wang, Y., and Tang, X. (2012). Identification of the toxic compounds produced by Sargassum thunbergii to red tide microalgae. Chin. J. Oceanol. Limn. 30, 778-785. doi: 10.1007/s00343-012-1294-5

Wells, M. L., Trainer, V. L., Smayda, T. J., Karlson, B. S. O., Trick, C. G., Kudela, R. M., et al. (2015). Harmful algal blooms and climate change: learning from the past and present to forecast the future. Harmful Algae 49, 68-93. doi: 10.1016/j.hal.2015.07.009

Wrzaczek, M., Brosche, M., and Kangasjärvi, J. (2013). ROS signaling loops production, perception, regulation. Curr. Opin. Plant Biol. 16, 575-582. doi: 10.1016/j.pbi.2013.07.002

Xia, B., Chen, B., Sun, X., Qu, K., Ma, F., and Du, M. (2015). Interaction of $\mathrm{TiO}_{2}$ nanoparticles with the marine microalga Nitzschia closterium: growth inhibition, oxidative stress and internalization. Sci. Total Environ. 508, 525-533. doi: 10.1016/j.scitotenv.2014.11.066

Xue, Q., Wang, R., Xu, W., Wang, J., and Tao, L. (2018). The stresses of allelochemicals isolated from culture solution of diatom Phaeodactylum tricornutum Bohlin on growth and physiology of two marine algae. Aquat. Toxicol. 205, 51-57. doi: 10.1016/j.aquatox.2018.10.004

Yang, A., Bellerby, R. G. J., Wang, Y., and Li, X. (2021). Growth and Nutrient Uptake Characteristics of Heterosigma akashiwo (Raphidophyceae) under Nitrogen and Phosphorus Concentrations in the East China Sea. Water 13:3166. doi: 10.3390/w13223166

Yang, C., Zhou, J., Liu, S., Fan, P., Wang, W., and Xia, C. (2013). Allelochemical induces growth and photosynthesis inhibition, oxidative damage in marine diatom Phaeodactylum tricornutum. J. Exp. Mar. Biol. Ecol. 444, 16-23. doi: 10.1016/j.jembe.2013.03.005

Yu, S., Li, C., Xu, C., Effiong, K., and Xiao, X. (2019). Understanding the inhibitory mechanism of antialgal allelochemical flavonoids from genetic variations: photosynthesis, toxin synthesis and nutrient utility. Ecotox. Environ. Safe. 177, 18-24. doi: 10.1016/j.ecoenv.2019.03.097

Zhang, C., Yi, Y. L., Hao, K., Liu, G. L., and Wang, G. X. (2013). Algicidal activity of Salvia miltiorrhiza Bung on Microcystis aeruginosa-towards identification of algicidal substance and determination of inhibition mechanism. Chemosphere 93, 997-1004. doi: 10.1016/j.chemosphere.2013.05.068

Zhang, T. T., He, M., Wu, A. P., and Nie, L. W. (2009). Allelopathic effects of submerged macrophyte Chara vulgaris on toxic Microcystis aeruginosa. Allelopathy J. 23, 391-402. doi: 10.1007/s002990050392

Conflict of Interest: The authors declare that the research was conducted in the absence of any commercial or financial relationships that could be construed as a potential conflict of interest.

Publisher's Note: All claims expressed in this article are solely those of the authors and do not necessarily represent those of their affiliated organizations, or those of the publisher, the editors and the reviewers. Any product that may be evaluated in this article, or claim that may be made by its manufacturer, is not guaranteed or endorsed by the publisher.

Copyright (c) 2022 Wang and Liu. This is an open-access article distributed under the terms of the Creative Commons Attribution License (CC BY). The use, distribution or reproduction in other forums is permitted, provided the original author(s) and the copyright owner(s) are credited and that the original publication in this journal is cited, in accordance with accepted academic practice. No use, distribution or reproduction is permitted which does not comply with these terms. 